\title{
The Mediating Effect of Person-Environment Fit on the Relationship between Organisational Culture and Staff Turnover
}

\author{
KamarulZaman Ahmad \\ College of Business Administration, Abu Dhabi University \\ Abu Dhabi, United Arab Emirates \\ E-mail: drkamphd@yahoo.com, Kamarul.zaman@adu.ac.ae
}

Received: July 18, 2011

Accepted: September 15, $2011 \quad$ Published: February 1, 2012

doi:10.5539/ass.v8n2p62

URL: http://dx.doi.org/10.5539/ass.v8n2p62

\begin{abstract}
The purpose of this study was to investigate the mediating effect of person-environment fit on the relationship between organisational culture and staff turnover intentions. Data were obtained from full-time employees who were working in private and public sectors from various organisations in Malaysia $(\mathrm{n}=204)$. Person-environment fit was found to be a significant mediator of the relationship between organisational culture and staff turnover intentions. This has wide-ranging implications for organisational development consultants who intend to shape the culture of various organisations, on the assumption that certain organisational cultures directly lead to certain desirable employee outcomes. Managers need to pay attention to not only their organisational culture such as training, rewards, teamwork and communication but to also ensure that they are aimed towards improving the fit between individuals and their work environment. Whereas previous research tends to look at P-E fit as a predictor of employee outcomes, this is one of the first few studies to provide evidence of $\mathrm{P}$-E fit as a mediator of the relationship between organisational culture and staff turnover intentions.
\end{abstract}

Keywords: Organisational culture, Person-environment fit, Staff turnover intentions

\section{Introduction}

Organisational culture has been consistently an important theme in management and business research for the past few decades due to its potential to affect organisationally and individually desired outcomes. For instance, there are many studies that looked at how organisational culture was a predictor of employee retention (Sheridan, 1992). Most people, especially younger employees understand and accept that loyalty towards their organisation is largely a losing proposition, and they are no longer willing to be dependent on their employers or accepting of organisational policies, practices and decisions, that do not meet their needs or career aspirations (Ooi and Arumugam, 2006). There are also many studies that found that the fit between the person and the environment (i.e., P-E fit) was an important predictor of work-related outcomes such as job satisfaction,organisational commitment and staff turnover (Cable and Judge, 1996; Kristof, 1996;KristofZimmerman and Johnson, 2005). In fact, from the various studies, cited in Kristof(1996), Kristof et al.,(2005) and Verquer, Beehr and Wagner (2003), P-E fit waspopularly viewed in the past, as a predictor or an independent variable affecting the dependent variable of employee outcomes.However, more recent research have begun to look beyond the simple bivariate relationships between P-E fit and job outcomes, and begun to discover the mediating and moderating variables that exist within this relationship (Jelinek and Ahearne, 2010; DaSilva, 2010). Yet, despite the current trend, according to our search in the Web of Science database, there was not a single empirical study that looked at how P-E fit was a mediating variable in the relationship between organisational culture (communication, teamwork, training and rewards) and work-related outcomes such as staff turnover intentions. DelCampo (2006) proposed such a relationship in their conceptual paper, but failed to follow up with an empirical research. The current research's primary or main objective is therefore to conduct an empirical study to test such a hypothesis.

Studies cited in the literature review are mainly from Western perspectives. However, Ahmad and Khairuddin (2003) have already shown that P-E fit theory can be applicable to a developing country such as Malaysia. This study can provide more evidence of such a contention. 


\section{Literature review}

\subsection{Organisational culture}

Organisational culture is generally seen as a set of key values, assumptions, understandings, and norms that is shared by members of an organisation and taught to new members as correct (Daft, 2005). It was argued that organisational culture may be the critical key that managers can use to direct the course of their firms (Smircich, 1983). The study on organisational culture can take on a multitude of aspects, including levels (visible, expressed values, and underlying assumptions), strength (strong or weak), and adaptiveness (adaptive or unadaptive). Culture can also be categorized as adaptability, achievement, clan, orbureaucratic (Daft, 2005); clan, adhocracy, hierarchy, or market (Cameron and Freeman, 1991; Quinn and Cameron, 1983; Quinn and Rohrbaugh, 1983); and communal,fragmented,networked, ormercenary (Goffee and Jones, 1998).

According to Wallach (1983), an organisation's culture can be a combination of three categories - bureaucratic, innovative or supportive. Rashid, Sambasivan and Johari (2003), found that companies listed in the Kuala Lumpur Stock Exchange were predominantly competitive, and value risk-taking, demanding goals, and that many manufacturers in the country had mercenary cultures that emphasized on strategy and winning in the marketplace. On the other hand, there were other companies that emphasise on tradition, loyalty, teamwork and personal commitment, which are among some of the values prevalent in Malaysian companies (Rashid, Sambasivan and Johari, 2004). Cooke and Rousseau (1998) stated that training, rewards, teamwork and organizational commitment are important aspects of culture, and it would be interesting to investigate whether they affect employee work-related outcomes, either directly or indirectly. With the indirect relationship, the relationship between organizational culture and turnover could be mediated by another variable. What makes this study unique is that the mediator chosen for this study is a variable that has been commonly viewed as an independent variable and a predictor of employee outcomes, rather than a mediator. This variable is the person-environment fit, and is explained in the next section.

\subsection{Person-Environment fit (P-E fit)}

Parsons' (1909) seminal work appears to be the first to have stressed the importance of both person and environment variables in vocational choice. There is an abundance of research that examined the degree of fit between the person and the environment i.e., person-environment fit or P-E fit, and how that is associated with satisfaction. Buboltz, Ebberwein, Watkins andSavickas (1995) discovered that in the last 20 years preceding their article, a total of 229 articles on P-E fit appeared in the Journal of Vocational Behavior and 75 articles on it appeared in the Career Development Quarterly. They also noted that, about 63 of the 229 articles on P-E fit in the Journal of Vocational Behavior and 22 out of the 75 in the Career Development Quarterly appeared during the last five years preceding their article. Kristofet al., (2005) have given one of the most up-to-date and comprehensive review of the previous studies on P-E fit. So have Piasentin and Chapman (2006) and Verquer, Beehr and Wagner (2003) when they conducted a meta-analytic review of 46 and 21 studies of P-E fit respectively. It still remains a current area of research interest (Ahmad, 2010; Bardi, Guerra and Ramdeny, 2009; Lyons, and O'Brien, 2006; Edwards, Cable, Williamson, Lambert, and Shipp, 2006; Kristof et al., 2005; Caldwell, Herold, and Fedor, 2004). The concept of P-E fit has been described as, "so pervasive as to be one of, if not the dominant conceptual forces in the field" (Schneider, 2001, p. 142). This constitutes evidence that the subject matter of P-E fit has not only been well established and extensively researched, but also remains a current area of interest (Kristof et al., 2005).

P-E fit was summarised by Edwards (1996, p. 292) as follows: "In essence, P-E fit embodies the premise that attitudes, behaviour and other individual level outcomes result not from the person or environment separately, but rather from the relationship between the two (Lewin, 1951; Murray, 1938; Pervin, 1989)". P-E fit is also of practical importance to managers. The environmental-demands and person-abilities fit underlie most models of personnel selection, in which the generally accepted paradigm is to analyse job demands, define abilities required to meet these demands and hire individuals with the requisite abilities (Schneider, 1978). Osipow (1987) summarised the issues associated with person-environment fit in the following three main questions: 1) How do we assess people? 2) How do we measure their environment? 3) How do we compare the two regarding degree and quality of fit?

Muchinskyand Monahan (1987, p. 268) explained that complementary fit, occurs when there is a "match between an individual's talents and the corresponding needs of the environment". By complementary, they meant that the "characteristics of an individual serve to make whole or complement the characteristics of an environment. The environment is seen as either deficient in or requiring a certain type of person in order to be effective" (Muchinsky and Monahan, 1987, p. 271). Supplementary fit, on the other hand, was said to exist when "a person fits into some environmental context because he or she supplements or embellishes or possesses 
characteristics which are similar to other individuals in this environment" (Muchinsky and Monahan, 1987, p. 268). However, Muchinskyand Monahan's (1987) categorisation is still incomplete. They defined complementary fit as comprising only the environment demand and personal abilities fit (i.e., D-A fit). Kristof (1996) expanded on Muchinskyand Monahan's (1987) definition to include S-V fit. In her article, she stated that it is important to be aware that there are two components of complementary fit. They are the Supply-Value fit (S-V fit) and the Demand-Abilities fit (D-A fit). From the S-V fit perspective, organisations supply financial, physical and psychological resources as well as the task-related, interpersonal and growth opportunities demanded and valued by employees (French, Caplanand Harrison, 1982; Livingstone, Nelson and Barr, 1997). Fit occurs when an organisation satisfies individuals' needs, desires or preferences (Kristof 1996). From the D-A fit perspective, organisations demand contributions from their employees in terms of their time, effort, commitment, knowledge, skills and abilities (French et al., 1982; Livingstone et al., 1997). D-A fit occurs when an individual has the abilities required to meet organisation demands (Kristof, 1996). In short, D-A fit focuses primarily on meeting the needs of others, while S-V fit focuses primarily on meeting one's own needs (Caplan, 1987; Livingstone et al., 1997).

Apart from categorizing P-E fit in terms of S-V or D-A fit, it is arguably more important to realise that P-E fit also operates simultaneously at three different levels: person-job fit (P-J fit), person-group fit (P-G fit) and person-organisation fit (P-O fit) and the cumulative effect of all three levels should be examined (Kristof, 1996; and Kristof et al., 2005). P-J fit relates to how the person is suited to the type of job he is currently holding, P-G fit is about how well the person gets along with his team members or colleagues, and P-O fit relates to how well the person's values and behavior fit with the organisation's culture.

As mentioned earlier in the introduction section,there are many studies that looked at how P-E fit was a predictor of such work-related outcomes. Vogel and Feldman (2009), and Lyons and O'Brien (2006),both treated P-E fit as a predictor of turnover intentions. Kieffer, Schinka and Curtis (2004) found that P-E fit was a predictor of job performance and work quality. P-E fit was even viewed as a dependent variable i.e., an outcome of change,in a study by Caldwell, Herold and Fedor (2004).

However, none of these studies have looked at how P-E fit could be a mediator of the relationship between turnover and a common organisational predictor such as organisational culture. DelCampo (2006) published a conceptual paper, but failed to conduct empirical research on this matter. There is a strong likelihood of support for such mediating relationship, based on similar research conducted by others. For instance, in various empirical studies, the fit between the person and the organisation (P-O fit) was found to be a mediator of the relationship between human resource policies and employee outcomes (Boon, Hartog, Boselie, andPaauwe, 2011), between CEO charismatic leadership and organisational commitment (Huang, Cheng and Chou, 2005) and between communication and organisational citizenship behaviour (Peng and Chiu, 2010). With the exception of Boon et al. (2011), the other studies mentioned in this paragraph, examined only P-O fit and not other forms of fit.

This research on the other hand examines P-E fit from a combination of all three perspectives, P-J, PG and P-O, as Edwards and Billsberry (2010) stressed that P-E fit is a multidimensional concept, and should be treated as such. In the current research, it could be argued that workers would achieve greater fit with their jobs (P-J fit), colleagues (P-G fit) and the organisation as a whole (P-O fit), when exposed to training that helps reduce that gap. Workers would clearly achieve greater $\mathrm{P}-\mathrm{G}$ fit if when exposed to teambuilding training. It can be theorised that improved organisational communication, would improve the fit between the worker and his/her organisation (P-O fit), and this will also spill-over into the other areas of fit such as the fit between the worker and his/her colleagues (P-G fit), and between the worker and his/her job (P-J fit). Similarly, it can be theorised that improved rewards and recognition will result in the worker perceiving himself/herself as fitting into the work environment as a whole, and this in turn will lead to positive work outcomes.

From the literature review, the following hypotheses were derived:

H1Organisational culture has a significant and relationship with staff turnover intentions.

H2 Person-environment fit has a significant mediating influence on the relationship between organisational culture and staff turnover intentions.

Figure 1 shows the conceptual framework and the hypothesised relationship between the variables.

$<$ Insert Figure 1 here $>$

\section{Data and Methodology}

Person-environment fit was measured by a total of twelve statements concerning P-O fit, P-G fit and P-J fit. Four items measured P-O fit and another four items measured P-J fit. All the said eight items were adapted from 
Cable and DeRue (2002). Examples of items are "The things that I value in life are very similar to the things that my organisation values" (person-organisation fit), and "There is a good fit between what my job offers me and what I am looking for in a job" (person-job fit). The remaining four items measured P-G fit, and these were adapted from Vogel and Feldman (2009).A sample item is "Working with other people in my group is one of the best parts of this job."

Respondents perception towards their organisation culture was collected via a total of fifteen statements pertaining to training and development (3-items), rewards and recognition (5-items), teamwork (4-items) and organisational communication (3-items), all taken from Cooke and Rousseau (1998). Examples of items include "Employees are encouraged to accept education and training within the organisation" (training and development); "The organisation's compensation system encourages team and individual contributions" (reward and recognition); "I am more comfortable working in a team rather than individually" (teamwork); and "I am satisfied with the way my organisation provides me with feedback" (communication).

Turnover intention was measured by three items from Cammann, Fichman, Jenkins and Klesh (1979). The items are "I probably look for a new job in the near future", "I will likely search for a new job in the near future" and "I often think of leaving the organisation". All the questions pertaining to person-environment fit, organisational culture, staff turnover intentions were measured using seven-point scales. Finally, demographic variables such as age, gender, marital status, ethnicity, job designation, highest level of education, tenure in the current organisation and organisation type were also collected.

Data was collected over a two-week period in the month of March 2010 using self-administered questionnaires. The target population of this study was full-time employees who were working in private and public sectors from various organisations in Malaysia. Three hundred questionnaires were distributed, either personally or by email, to Malaysian employees in administration, supervisory, managerial, professional and technical positions. Two hundred and thirteen questionnaires were returned on time. However, nine were incomplete, and only 204 questionnaires were usable yielding a response rate of $68 \%$. This research complies with Sekaran's (2005) rule of thumb that says that sample sizes larger than 30 and less than 500 are appropriate for most research.

\section{Description of Results}

Details of the demographics of the sample are given in Table 1.

$<$ Insert Table 1 here $>$

As depicted in Table 1, there were slightly more female respondents (54.4\%) than male respondents (45.6\%). There were slightly more single respondents (52.9\%) than married ones (46.1). Most of the respondents fell into the 20 to 29 years old age group (52\%), followed closely by respondents aged 30-39 years $(41.2 \%)$. Chinese formed the major ethnic group (42.2\%) followed by Malays $(35.3 \%)$ and Indians (22.5\%). Most of the respondents were degree holders $(82.8 \%)$, held middle-management positions $(69.1 \%)$, and were from the services sector $(68.1 \%)$. In terms of tenure, $32.4 \%$ of the respondents served less than 2 years, $37.7 \%$ served between 2-5 years, 24\% served between 6-10 years and only 5.9\% served more than 10 years.

Reliability tests were conducted, and results showed that all the instruments used in this study have cronbach alpha figures above 0.7 , and can be considered to be reliable (Nunnally, 1978). The reliability scores are displayed in Table 2.

$<$ Insert Table 2 here $>$

According to Kaiser (1974), the Kaiser-Mayer-Ohlin (KMO) measure should be at least 0.6. More precisely, Kaiser (1974) suggested that KMO measures in the $0.9 \mathrm{~s}$ be characterised as marvelous, in the $0.8 \mathrm{~s}$ be meritorious, in the $0.7 \mathrm{~s}$ as middling, in the $0.6 \mathrm{~s}$ as mediocre, in the $0.5 \mathrm{~s}$ as miserable, and below 0.5 as unacceptable. Bartlett's (1954) test of sphericity is significant when $p<0.001$. It can be seen from Table 3that both these requirements are met by all the main variables in this study.

$<$ Insert Table 3 here $>$

Correlation analyses were conducted, and results showed that organisational culture was significantly negatively related with turnover intention $(\mathrm{r}=-.512, \mathrm{p}<0.01)$. Results are displayed in Table 4 .

The technique of testing for mediating effects was adopted from Baron and Kenny (1986). One of the most recent use of the said technique is Malik, Waheed and Malik (2010). Mediational hypothesis generally assumes that the effect of the independent variable on the dependent variable is mediated by a mediating variable. Baron and Kenny (1986) prescribesthe following equations with respect to the independent variable (IV), mediating variable (M) and dependent variable (DV). 
1_A variable functions as a mediator when it meets the following

1) The IV must be related to the $M$.

2) The IV must be related to the DV.

3) M must be related to the DV.

4) The strength of the relationship in equation 3 must be less than equation 2

Perfect mediation occurs when IV is not related to DV, when M is controlled. Preacher and Hayes (2004) also concurred by stating that there is evidence for complete mediation when the effect of IV on DV with the inclusion of $\mathrm{M}$ is insignificant i.e., not significantly different from zero. However, when the effect of IV on DV with the inclusion of $\mathrm{M}$ is reduced in magnitude, but remains significant, there is evidence for partial mediation (Preacher and Hayes, 2004). Partial mediation is more realistic than complete mediation, in social studies, because of the many causes of behaviour (Baron and Kenny, 1986). Another way of examining this is to check the $\mathrm{R}^{2}$ between IV and DV, without M, and with M (Ismail, Mohamed, Sulaiman, Mohamad, \&Yusof, 2011).

$<$ Insert Table 4 here $>$

Table 4 shows the results of the regression analyses. In equation 1, a simple regression analysis was conducted between the independent variable of organisational culture and the mediating variable of P-E fit. Results showed that organisational culture was significantly related with P-E fit $(r=.334, \beta=.603, p<.01)$. In equation 2 , IV (organisational culture) is negatively related with DV (turnover intention; $r=-.512, \beta=-.618, \mathrm{p}<.01$ ), thus supporting H1.

In equation 3, a simple regression analysis was conducted, and results showed that the M(P-E fit) was significantly related withDV (turnover intention; $\mathrm{r}=-.469, \beta=-.314, \mathrm{p}<.01$ ). Table 4 show the results.Regarding the $4^{\text {th }}$ criteria, it can be observed that the strength of the relationship in equation $3(r=-.469, \beta$ $=-.314)$ is less than in equation $2(r=-.512, \beta=-.618)$ (negative signs are ignored as they representthe direction of the relationship, and not the magnitude).

Finally, a regression analysis was conducted with the IV and the DV only at first, and then with M included in the equation. Table 5 shows the results. The $\beta$ value was -0.618 when $\mathrm{M}$ was not included in the equation, but then dropped to- 0.509 when $\mathrm{M}$ was included in the equation. Thus, there is no evidence of full mediation, but rather a partial mediation effectbecause the $\beta$ value did not go to zero, and was reduced slightly instead. Also the $\mathrm{R} 2$ between IV and DV was 0.262 without the $\mathrm{M}$, and it increased to 0.323 when $\mathrm{M}$ was introduced into the equation as an additional independent variable. Therefore the incremental change in R2 was a slight increase of only 0.061 giving evidence of a partial mediating effect of M (P-E fit), thus partially supporting H2.

$<$ Insert Table 5 here $>$

\section{Conclusions}

\subsection{Hypotheses testing}

Two hypotheses were tested and supported. Research results show that organisational culture has a significant and negative relationship with staff turnover intentions (H1). Person-environment fit has a significant mediating influence on the relationship between organisational culture and staff turnover intentions(H2).

\subsection{Implications for research and practice}

Whereas previous research looked at person-environment fit as a predictor of job outcomes such as staff turnover intentions, this research, on the other hand, looked at person-environment fit as a mediator of the relationship between organisational culture and the said job outcome. This has wide-ranging implications for organisational development consultants who intend to shape the culture of various organisations, on the assumption that certain organisational cultures lead to certain desirable employee outcomes. Results of this research suggest that the relationship between organisational culture and staff turnover intentions is not direct, but rather it is mediated by another variable, the person-environment fit. This means that aspects of organisational culture such as training, rewards, teamwork and communication, must be aimed at improving overall person-environment fit, and this in turn will lead to reduced staff turnover intentions. As mentioned in the literature review, several studies cited by Vogel and Feldman (2009), suggested that P-E fit is a predictor of staff turnover intentions, and the current research supports this. The contribution of the current research is that organisational culture, is an antecedent of person-environment fit, and the practical implication is that organisational development consultants should attend to the relevant aspects of organisational culture such as training, rewards, teamwork and communication, 
with the purpose of improving overall person-environment fit. This will then increase the chances of reducing staff turnover intentions.

\subsection{Limitations}

This study is cross-sectional and no conclusions can be drawn about the direction of causality in this research. Another limitation of this research is the relatively small sample size of 204 respondents from the city of Kuala Lumpur, Malaysia. This may not be representative of the rural areas found in other parts of Peninsular Malaysia. The respondents in the sample were selected using convenience sampling and were also mostly young executives from the services sector. Future research should cover other industry sectors and also civil servants. Thus, findings of this study cannot be generalised to the general Malaysian population. On a positive note however, even though most of the studies cited in the literature review are from western perspectives, it is refreshing to note that a similar perspective can be applied to this limited sample in Malaysia.

\section{References}

Ahmad, K. Z. \& Khairuddin, M.M. (2003). Person-environment fit perceptions and satisfaction at work. Malaysian Management Journal, 7(1), 35-46.

Ahmad, K. Z. (2010). Person-environment fit approach to intolerance of inequity and free-riders. International Business Research, 3(1), 35-42.

Bardi, A. Guerra, V. M. \& Ramdeny, S. D. (2009). Openness and ambiguity intolerance: Their differential relations to well-being in the context of academic life transition. Personality and Individual Differences, 47, 219-223. http://dx.doi.org/10.1016/j.paid.2009.03.003

Baron, R. M. \& Kenny, D. A. (1986). Moderator-mediator variable distinction in social psychological research: conceptual, strategic and statistical considerations. Journal of Personality and Social Psychology, 6, 1173-1182. http://dx.doi.org/10.1037/0022-3514.51.6.1173

Bartlett, M. S. (1954). A note on the multiplying factors for various chisquare approximations. Journal of the Royal Statistical Society, 16, 296-298.

Boon, C., Hartog, D. N. D, Boselie, P. \& Paauwe, J. (2011). The relationship between perceptions of HR practices and employee outcomes: examining the role of person-organisation and person-job fit. The international Journal of Human Resource Management, $22(1), \quad 138$. http://dx.doi.org/10.1080/09585192.2011.538978

Buboltz, W. C., Ebberwein, C., Watkins, C. E. \& Savickas, M. L. (1995). A comparison of the content, authors and institutions represented in the Career Development Quarterly and the Journal of Vocational Behavior. Journal of Vocational Behavior, 46, 216-226. http://dx.doi.org/10.1006/jvbe.1995.1014

Cable, D. M. \& DeRue, D. S. (2002). The convergent and discriminant validity of subjective fit perceptions. Journal of Applied Psychology, 87, 875-884. http://dx.doi.org/10.1037/0021-9010.87.5.875

Cable, D. M. \& Judge, T. A. (1996). Person-organization fit, job choice decisions, and organizational entry. Organizational Behaviour and Human Decision Processes, 67(3), 294-311. http://dx.doi.org/10.1006/obhd.1996.0081

Caldwell, S. D., Herold, D. M. \& Fedor, D. B. (2004). Toward an understanding of the relationships among organizational change, individual differences, and changes in person-environment fit: a cross-level study. Journal of Applied Psychology, 89(5), 868-882. http://dx.doi.org/10.1037/0021-9010.89.5.868

Cameron, K. S. \& Freeman, S. J. (1991). Cultural congruence, strength, and type: relationships to effectiveness. Research in Organizational Change and Development, 5, 23-58.

Cammann, C., Fichman, M., Jenkins, D. \& Klesh, J. (1979). The Michigan Organisational Assessment Questionnaire. Unpublished Manuscript, University of Michigan Library.

Caplan, R. D. (1987). Person-environment fit theory and organizations: commensurate dimensions, time perspectives, and mechanisms. Journal of Vocational Behavior, 31, 248-267. http://dx.doi.org/10.1016/0001-8791(87)90042-X

Cooke, R. A. \& Rousseau, D. M. (1998). Behavioural norms and expectations: A quantitative approach to the assessment of organizational culture. Group and Organizational Studies, 13(3), 245-273. http://dx.doi.org/10.1177/105960118801300302

Daft, R. L. (2005). The Leadership Experience, $3^{\text {rd }}$ ed. Thomson-Southwestern: Canada. 
DaSilva, N. Hutcheson, J. \& Wahl, G. D. (2010). Organizational strategy and employee outcomes: a person-organization fit perspective. The Journal of Psychology, 144(2), 145-161. http://dx.doi.org/10.1080/00223980903472185

DelCampo, R. G. (2006). The influence of Culture Strength on Person-Organization Fit and Turnover. International Journal of Management, 23(3), 465-469

Edwards, J. R. \& Billsberry, J. (2010). Testing a Multidimensional Theory of Person-Environment Fit. Journal of Managerial Issues, 22(4), 476-493.

Edwards, J. R. (1996). An examination of competing versions of the person-environment fit approach to stress. Academy of Management Journal, 39(2), 292-339. http://dx.doi.org/10.2307/256782

Edwards, J. R., Cable, D. M., Williamson, I. O., Lambert, L. S. \& Shipp, A. J. (2006). The phenomenology of fit: Linking the person and environment to the subjective experience of person-environment fit. Journal of Applied Psychology, 91(4), 802-827. http://dx.doi.org/10.1037/0021-9010.91.4.802

French J. R. P., Caplan, R. D. \& Harrison. R. V. (1982). The Mechanisms of Job Stress and Strain. John Wiley \& Sons, London.

Goffee, R. \& Jones, G. (1998). The Character of a Corporation: How Your Company's Culture Can Make or Break Your Business. Harper Business, London.

Huang, M. P., Cheng, B. S. \& Chou, L. F. (2005). Fitting in organizational values. The mediating role of person-organization fit between CEO charismatic leadership and employee outcomes. International Journal of Manpower, 26(1), 35-110. http://dx.doi.org/10.1108/01437720510587262

Ismail, A., Mohamed, H. A., Sulaiman, A. Z., Mohamad, M. H. \& Yusuf, M. H. (2011). An empirical study of the relationship between transformational leadership, empowerment and organizational commitment. Business and Economics Research Journal, 2(1), 89-107.

Jelinek, R. \& Ahearne, M. (2010). Be careful what you look for: the effect of trait competitiveness and long hours on salesperson deviance and whether meaningfulness of work matters. Journal of Marketing Theory and Practice, 18(4), 303-321. http://dx.doi.org/10.2753/MTP1069-6679180401

Kaiser, H. (1974). An index of factorial simplicity. Psychometrika, 39, 31-36. http://dx.doi.org/10.1007/BF02291575

Kieffer, K. M., Schinka, J. A. \& Curtis, G. (2004). Person-environment congruence and personality domains in the prediction of job performance and work quality. Journal of Counseling Psychology, 51(2), 168-177. http://dx.doi.org/10.1037/0022-0167.51.2.168

Kristof, A. (1996). Person-organisation fit: an integrative review of its conceptualisations, measurement, and implications. Personnel Psychology, 49, 1-49. http://dx.doi.org/10.1111/j.1744-6570.1996.tb01790.x

Kristof, A., Zimmerman, R. D. \& Johnson, E. C. (2005). Consequences of individuals' fit at work: a meta-analysis of person-job, person-organization, person-group and person-supervisor fit. Personnel Psychology, 58, 281-342. http://dx.doi.org/10.1111/j.1744-6570.2005.00672.x

Lewin, K. (1951). Field Theory in Social Science. Harper: New York.

Livingstone, L. P., Nelson, D. L. \& Barr, S. H. (1997). Person-environment fit and creativity: an examination of supply-value and demand-ability versions of fit. Journal of Management, 23, 2, $119-146$.

Lyons, H. Z. \& O'Brien, K. M. (2006). The role of person-environment fit in the job satisfaction and tenure intentions of African American employees. Journal of Counseling Psychology, 53(4), 387-396. http://dx.doi.org/10.1037/0022-0167.53.4.387

Malik, O. F., Waheed, A. \& Malik, K. U. R. (2010). The mediating effects of job satisfaction on role stressors and affective commitment. International Journal of Business and Management, 5(11), 223-235.

Muchinsky, P. M. \& Monahan, C. J. (1987). What is person-environment congruence? Supplementary versus complementary models of fit. Journal of Vocational Behavior, 31, 268-277. http://dx.doi.org/10.1016/0001-8791(87)90043-1

Murray, H. A. (1938). Explorations in Personality. Houghton Mifflin: Boston.

Nunnally, J. O. (1978). Psychometric Theory. McGraw-Hill: New York. 
Ooi, K. B. \& Arumugam, V. (2006). The influence of corporate culture on organizational commitment: Case study of semiconductor organisations in Malaysia. Sunway Academic Journal, 3, 99-115.

Osipow, S. H. (1987). Applying person-environment theory to vocational behavior. Journal of Vocational Behavior, 31, 333-336. http://dx.doi.org/10.1016/0001-8791(87)90047-9

Parsons, F. (1909). Choosing a Vocation. Houghton Mifflin: Boston, MA.

Peng, J. C. \& Chiu, S. F. (2010). An Integrative Model Linking Feedback Environment and Organizational Citizenship Behavior. Journal of Social Psychology, 150(6), 582-607. http://dx.doi.org/10.1080/00224540903365455

Pervin, L. A. (1989). Persons, situations, interactions: the history and a discussion of theoretical models. Academy of Management Review, 14(3), 350-360.

Piasentin, K. A. \& Chapman, D. S. (2006). Subjective person-organisation fit: Bridging the gap between conceptualisation and measurement. Journal of Vocational Behaviour, 69, 202-221. http://dx.doi.org/10.1016/j.jvb.2006.05.001

Preacher, K. J. \& Hayes, A. F. (2004). SPSS and SAS procedures for estimating indirect effects in simple mediation models. Behavior Research Methods, Instruments, \& Computers, 36(4), 717-731. http://dx.doi.org/10.3758/BF03206553

Quinn, R. E. \& Cameron, K. (1983). Organizational life cycles and sifting criteria of effectiveness: Some preliminary evidence. Management Science, 29, 33-51. http://dx.doi.org/10.1287/mnsc.29.1.33

Quinn, R. E. \& Rohrbaugh, J. (1983). A spatial model of effectiveness criteria: Towards a competing values approach to organizational analysis. Management Science, 29, 363-77. http://dx.doi.org/10.1287/mnsc.29.3.363

Rashid, M. Z. A., Sambasivan, M. \& Johari, J. (2003). The influence of corporate culture and organizational commitment on performance. Journal of Management Development, 22(8), 708-28. http://dx.doi.org/10.1108/02621710310487873

Schneider, B. (1978). Person-situation selection: a review of some ability-situation interaction research. Personnel Psychology, 31, 281-297. http://dx.doi.org/10.1111/j.1744-6570.1978.tb00447.x

Schneider, B. (2001). Fits about fit. Applied Psychology: An International Review, 50, 141-152. http://dx.doi.org/10.1111/1464-0597.00051

Sekaran, U. (2005). Research Methods for Business. A skill building approach. $3^{\text {rd }}$ ed. John Wiley and Sons, New York.

Sheridan, J. E. (1992). Organisational Culture and Employee Retention. Academy of Management Journal, 35(5), 1036-1056. http://dx.doi.org/10.2307/256539

Smircich, L. (1983). Concepts of culture and organizational effectiveness. Administrative Science Quarterly, 28(3), 339-58. http://dx.doi.org/10.2307/2392246

Verquer, M. L., Beehr, T. A. \& Wagner, S. H. (2003). A meta-analysis of relations between person-organization fit and work attitudes. Journal of Vocational Behavior, 63, 473-489. http://dx.doi.org/10.1016/S0001-8791(02)00036-2

Vogel, R. M. \& Feldman, D. C. (2009). Integrating the levels of person-environment fit. The roles of vocational fit and group fit. Journal of Vocational Behavior, 75, 68-81. http://dx.doi.org/10.1016/j.jvb.2009.03.007

Wallach, E. J. (1983). Individuals and organizations: The cultural match. Training and Development Journal, 37, 29-36. 
Table 1. Demographics

\begin{tabular}{|c|c|c|}
\hline Characteristics & Frequency & Percentage $(\%)$ \\
\hline \multicolumn{3}{|l|}{ Age } \\
\hline$\overline{20-29}$ & 106 & 52.0 \\
\hline $30-39$ & 84 & 41.2 \\
\hline $40-49$ & 9 & 4.4 \\
\hline 50 and above & 5 & 2.5 \\
\hline \multicolumn{3}{|l|}{ Gender } \\
\hline Male & 93 & 45.6 \\
\hline Female & 111 & 54.4 \\
\hline \multicolumn{3}{|l|}{ Marital status } \\
\hline Single & 108 & 52.9 \\
\hline Married & 94 & 46.1 \\
\hline Divorced/widowed & 2 & 1.0 \\
\hline \multicolumn{3}{|l|}{ Ethnicity } \\
\hline Malay & 72 & 35.3 \\
\hline Chinese & 86 & 42.2 \\
\hline Indian & 46 & 22.5 \\
\hline \multicolumn{3}{|l|}{ Education } \\
\hline Secondary & 3 & 1.5 \\
\hline Cert/Diploma & 5 & 2.5 \\
\hline Degree & 169 & 82.8 \\
\hline Post Graduate & 27 & 13.2 \\
\hline \multicolumn{3}{|l|}{ Job Position } \\
\hline Top Management & 6 & 2.9 \\
\hline Middle Management & 141 & 69.1 \\
\hline Technical Employee & 12 & 5.9 \\
\hline Non Management & 6 & 2.9 \\
\hline Skilled Professional & 34 & 16.7 \\
\hline Others & 5 & 2.5 \\
\hline \multicolumn{3}{|l|}{ Tenure } \\
\hline Less than 2 years & 66 & 32.4 \\
\hline $2-5$ years & 77 & 37.7 \\
\hline $6-10$ years & 49 & 24.0 \\
\hline More than 10 years & 12 & 5.9 \\
\hline \multicolumn{3}{|l|}{ Organisation type } \\
\hline Services & 139 & 68.1 \\
\hline Manufacturing & 22 & 10.8 \\
\hline Property & 4 & 2.0 \\
\hline Construction & 4 & 2.0 \\
\hline Government & 10 & 4.9 \\
\hline Others & 25 & 12.3 \\
\hline
\end{tabular}

Table 2 . Reliability scores

\begin{tabular}{llll}
\hline & & & Reliability Test \\
\hline Variable & Mean & Std Deviation & Cronbach Alpha \\
\hline Person-environment Fit & 4.29 & .079 & .075 \\
\hline Training and development & 4.77 & .97 & .77 \\
\hline Rewards and recognition & 4.22 & .99 & .71 \\
\hline Teamwork & 5.01 & .82 & .74 \\
\hline Turnover intention & 4.27 & .66 & .82 \\
\hline
\end{tabular}


Table 3. KMO measures of sampling adequacy and Bartlett's Test

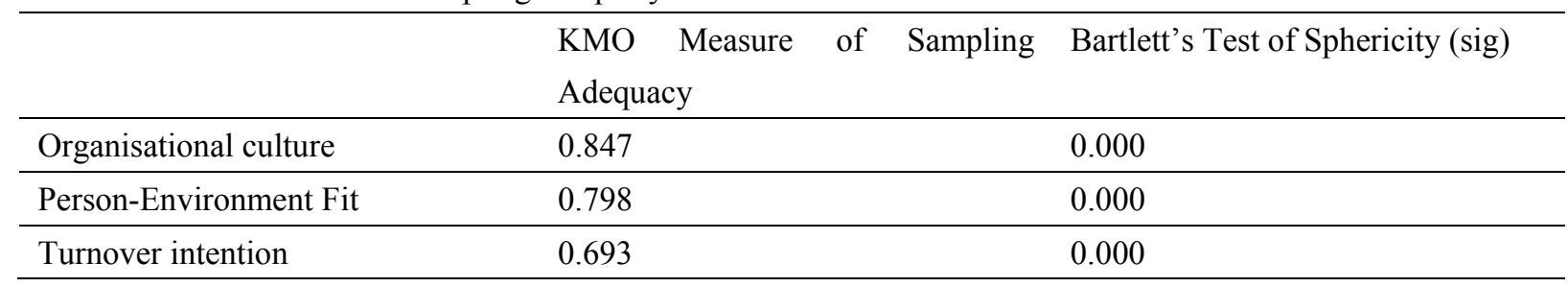

Table 4. $r$ and $\beta$ values

\begin{tabular}{lll}
\hline & OC & PE \\
\hline Organisational culture (OC) & 1 & \\
\hline Person Environment Fit (PE) & $\mathrm{r}=.334^{* *}$ & 1 \\
& $\beta=.603$ & \\
& (equation 1) & \\
\hline Turnover Intention (T) & $\mathrm{r}=-.512^{* *}$ & $\mathrm{r}=-.469^{* *}$ \\
& $\beta=-.618$ & $\beta=-.314$ \\
& (equation 2) & (equation 3)
\end{tabular}

**Correlation is significant at the 0.01 level ( 1 tailed)

*Correlation is significant at the 0.05 level ( 1 tailed)

Note: Equation 3 must be less than equation 2

Table 5. Tests of direct and mediating relationships

\begin{tabular}{lll}
\hline Variables & \multicolumn{2}{c}{ Turnover intention $(\mathrm{T})$} \\
\cline { 2 - 3 } & $\begin{array}{l}\text { Direct Effect } \\
(\mathrm{OC} \text { on } \mathrm{T})\end{array}$ & $\begin{array}{l}\text { Mediated Effect of P-E Fit }(\mathrm{OC} \\
\& \text { P-E on T) }\end{array}$ \\
\hline Organisational & $\beta=-0.618^{* *}$ & $\beta=-0.509^{* *}$ \\
Culture & $\mathrm{r}=-0.512$ & $\mathrm{r}=-0.568$ \\
\hline $\mathrm{r}^{2}$ & $0.262^{* *}$ & $0.323^{* *}$ \\
\hline$\Delta \mathrm{r}^{2}$ & & 0.061 \\
\hline $\mathrm{f}$ & $100.624^{* *}$ & $64.579^{* *}$ \\
\hline
\end{tabular}

*** Significant at the 0.01 level (1-tailed)

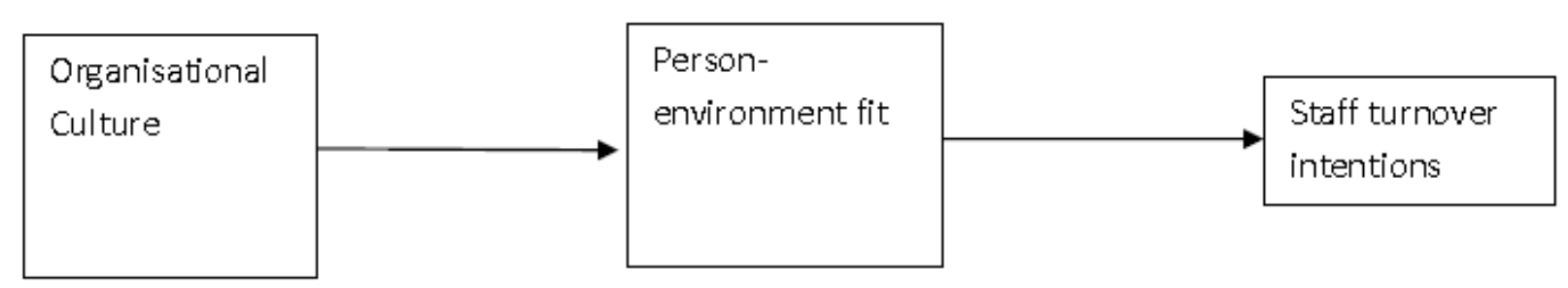

Figure 1. Conceptual framework 